\title{
A educação ambiental: entornos pós-modernos
}

\author{
Alik Wunder, Erica Speglich, Fabiana Aparecida de Carvalho, \\ Antonio Carlos R. de Amorim ${ }^{1}$ \\ Faculdade de Educação da Unicamp
}

resumo: Este trabalho foi escrito com a intenção de apontar dobras no campo da pesquisa em educação ambiental que foram produzidas em três dissertações de Mestrado, cujas inspirações teórico-metodológicas recaem sobre o pósmodernismo e o pós-estruturalismo. Enfatizando os processos de desnaturalização da pesquisa em educação ambiental como pesquisa científica, são apresentadas três diferentes potencialidades a serem exploradas em educação ambiental, extraídas de estudos sobre narrativas, experiências, representações culturais e memória.

palavras-chave: Identidades, Pós-modernismo, Cultura.

abstract: This paper has been written aiming to point out a few folds on the environmental education field which were produced in three Master dissertations based on inspirations from postmodernism and poststructuralism theoretical and methodological focuses. Emphasizing processes of denaturalization of environmental education research as a scientific research, three different potentialities are going to be introduced in this paper, extracted from studies about narratives, experiences, cultural representations and memory.

keywords: Identities, Postmodernism, Culture.

\footnotetext{
1 e-mail: alik@unicamp.br, erica@cria.org.br, fadhra@yahoo.com.br, acamorim@unicamp.br Financiamento: FAPESP e CNPq.
} 
Das aventuras do Grupo de Estudos Impregnações da Pósmodernidade, dentro do Grupo de Estudos e Pesquisa em Formação de Professores da Área de Ciências, na Faculdade de Educação da Unicamp, estilhaçaram-se algumas idéias, conceitos e propostas que ganharam forma em três dissertações de Mestrado cujas problemáticas giraram em torno da educação ambiental. Para este artigo em especial, trazemos aportes teórico-metodológicos que foram fios de tecedura desses trabalhos. Nossa intenção é apontar contornos que o campo da educação ambiental pode ganhar quando se dobra sobre perspectivas pós-modernistas. Linda Hutcheon (2002) nos traz as discussões de como a pós-modernidade e o pós-modernismo têm sido cunhados nos círculos filosóficos.

O pós-modernismo tenta instalar e reforçar, tanto quanto, escavar e subverter, as convenções e pressupostos que parecem nos desafiar. Assim, parece razoável dizer que o intuito inicial dos pós-modernos é des-naturalizar [sic] alguns conceitos dominantes de nosso modo de vida, é apontar que coisas que nós inconscientemente experienciamos como 'naturais' (que poderiam incluir, inclusive, o capitalismo, o patriarcado, o liberalismo) são, de fato, 'culturais'; feit[a]s por nós mesmos, não dad[a]s para nós. Mesmo a natureza, do ponto de vista do pós-modernismo, não cresce em árvores. (p. 1-2).

Para ela, a pós-modernidade seria "a designação de um período on 'condição' social e filosófica (...) envolvendo uma crítica ao humanismo e positivismo, e uma investigação da relação de ambos com nossas noções de subjetividade".

$\mathrm{Na}$ dissertação de Fabiana Aparecida de Carvalho, denominada Outros... com textos. Traços da Biologia em obras de Monteiro Lobato, as análises das relações entre biologia e literatura, na composição de representações sobre natureza, basearam-se nos conceitos de traço e contexto de Jacques Derrida. Já na dissertação de Alik Wunder, denominada Encontro de Águas na Barra do Ribeira - imagens entre experiências e identidades na escola, os conceitos de experiência e identidades para Stuart Hall e Jorge Larrosa foram fontes de inspiração. $\mathrm{Na}$ dissertação de Mestrado de Érica Speglich, Entre as Asas da Serra, a intenção foi produzir uma escrita sobre o trabalho desenvolvido pela autora e por duas professoras que trabalham tanto numa escola pública 
quanto numa ONG ambiental, capturando dimensões e expressões do movimento denominado "resgate histórico-cultural", que, em seus múltiplos desdobramentos, traz/produz/inventa/reconstitui multifacetadamente sujeitos para um novo contexto cultural tensionado pelas relações entre turismo e tradições locais.

As seções seguintes foram extraídas dos textos das três dissertações, em especial os conceitos que movimentaram as análises e os extratos de materiais escritos e/ou orais, constructos das pesquisas que por vezes são considerados "dados".

\section{Registros em narrativas: experiências e identidades flutuantes de uma pesquisa}

$\mathrm{Na}$ dissertação "Encontro de Águas" na Barra do Ribeira: imagens entre experiências e identidades na escola, a escritura do texto da pesquisa fezse como uma busca de aproximação entre as linguagens das ciências e das artes, nas interfaces entre as narrativas escritas e imagéticas. A criação de diferentes identidades narrativas pela pesquisadora aproxima sua escritura a uma ficção, a uma versão entre outras possíveis. A linguagem procurou ser trazida como criação e não tentativa de reprodução nua e crua dos fatos, como matéria-prima e não instrumento da pesquisa.

O texto é a história de uma experiência de pesquisa de Mestrado realizada na Barra do Ribeira (Iguape). As perguntas que direcionam a pesquisa vão sendo tecidas e destecidas com os fios diversos colhidos das experiências em campo e das experiências de leituras. A escritura é, assim, uma busca constante de trazer para o campo científico os fluxos e refluxos da experiência como pesquisadora e educadora, os "saberes da experiência”.

Para Jorge Larrosa, a experiência é "o que nos acontece" e não "o que acontece", e o saber da experiência são os sentidos que damos a este acontecido em nós, então, saberes da experiência não poderiam ser vinculados a conhecimentos e verdades universais e únicas: "trata-se de um saber finito, ligado à experiência de um indivíduo ou de uma comunidade 
humana particular [...], por isso, o saber da experiência é um saber particular, subjetivo, relativo, contingente e pessoal" (2001, s/p).

Essa perspectiva menos essencial e fixa de saberes nos leva a compreendê-los como constante transformação. Tendo como característica metodológica a pesquisa participante, que se propõe a transformar e transforma-se na relação, os saberes gerados por esta pesquisa buscavam também esse movimento.

No ano de 2000, inicia-se na escola da Barra do Ribeira (Iguape - SP) um projeto de educação ambiental desenvolvido por jovens da comunidade, monitores ambientais, que buscavam, para além do trabalho com o turismo ecológico, a sua organização coletiva pela Associação de Monitores Ambientais de Iguape (AMAI), bem como seu papel como educadores na comunidade. A pesquisadora via nesse trabalho intensidades de saberes buscando permear o espaço escolar. Acompanhou durante dois anos o projeto observando a interação entre os saberes da experiência dos monitores ambientais e dos professores e destes com os seus, bem como as relações de reconhecimento e estranhamento entre esses diferentes profissionais da educação. Buscou contribuições desse olhar para a discussão sobre a relação entre escola e a comunidade e entre os saberes que se constroem nesses diferentes espaços educativos num contexto de conflito socioambiental.

Partindo do conceito de experiência de Jorge Larrosa, os saberes de experiência dos professores, dos monitores ambientais e da pesquisadora entrariam em diálogo à medida que se transformassem durante ou depois da própria experiência de interação, já que "ninguém pode aprender a experiência de outro a menos que essa experiência seja revivida e tornada própria" (LARROSA, 2001, s.p). O diálogo de saberes da experiência entendido como o vivenciar conjunto de experiências, o "reviver e tornar próprio", subentende a possibilidade do encontro, da interação e do deixar-se permear pelo outro e ao mesmo tempo diferenciar-se dele. E esse encontro com o outro remete-nos, ao mesmo tempo, a nós mesmos, à construção de nossa própria identidade.

Os diversos encontros ocorridos entre a pesquisadora e as situações ligadas direta ou indiretamente ao projeto de educação ambiental foram sendo registrados de várias formas. Essas diferentes 
maneiras de trazer os sentidos das experiências vividas em campo foram revelando múltiplas identidades narrativas, que recriavam os chamados "dados" da pesquisa. Ao retornar do campo, entregava-se à difícil tarefa de garimpar, selecionar, reordenar os fatos, por meio de uma escrita descritiva. Esses registros traziam o desenho de um bordado, o processo da pesquisa participante e as decisões e atuações coletivas que foram se conformando durante o trabalho. Desenho que buscava alinhar pessoas-fios com suas diversas idéias, pensamentos, desejos, expectativas, jeitos de fazer, conflitos, cores, espessuras, texturas, pontos e nós - numa conformação geral, coletiva, mais ou menos coesa e linear.

Mas no avesso outros desenhos se formavam, descontínuos na mudança de cores e pontos, interrompidos por espaços vazios e fios soltos, cada um apontando para uma direção diferente. A desconexão do cotidiano. Isso pedia uma outra escrita, um segundo exercício narrativo, no qual também coubessem as descontinuidades do tempo, as circularidades da memória, os fragmentos, os acontecimentos sem antes nem depois. Essa ânsia por uma segunda maneira de contar o vivido foi interagindo e intercruzando-se com uma terceira narrativa: a fotografia.

Ao mesmo tempo em que os registros escritos eram feitos depois do campo, um álbum fotográfico se fazia paralelo. Paralela, a linguagem imagética assumia sua especificidade, sua diferença em relação às palavras.

E mesmo marcadas por suas diferenças inerentes, as palavras e as imagens encontravam-se em alguns momentos, os fios paralelos por vezes entremeavam-se, transformando um ao outro. E nesse entremear, a influência da fotografia na escrita narrativa ia ficando cada vez mais marcante, tanto pela própria experiência de fotografar em campo quanto pela experiência do vaguear posterior pelas imagens reveladas. Iniciemos por esta segunda experiência.

$\mathrm{O}$ vaguear do olhar sobre uma imagem reconstitui a dimensão do tempo. $\mathrm{O}$ vaguear do olhar é circular, tende a voltar a contemplar elementos já vistos. Assim, o "antes" se torna "depois" e o "depois" se torna "antes". O tempo projetado pelo olhar sobre a imagem é o eterno retorno!” (FLÜSSER, 1985, 
p. 14). "[...] as certezas desabam e se confundem à medida que meu olhar, mergulhado nela cada vez se dissolve e se renova. A fotografia não funciona sem a nossa participação, nosso olhar a desmantela e a reconstrói a cada captura. (SAMAIN, 1993, p. 4).

O contato com as fotografias da escola, dos rios, dos mares, das ruas da Barra, das pessoas possibilitou a abertura a um olhar contemplativo, circular, que não se fechava em explicações de processos. As fotografias pareciam levar a um pensar mais solto e aberto à experiência da novidade, da evasão, do imaginar:

A propósito de qualquer imagem que nos impressiona, devemos indagar-nos: qual o arroubo lingüístico que essa imagem libera em nós? [...] Para bem sentir o papel imaginante da linguagem, é preciso procurar pacientemente, a propósito de todas as palavras, os desejos de alteridade, os desejos de duplo sentido, os desejos da metáfora [...] Pela imaginação abandonamos o curso ordinário das coisas [...] Imaginar é ausentar-se, lançar-se a uma vida nova. (BACHELARD, 2001, p. 3).

Esses contatos com a fotografia foram fazendo circular outras palavras menos preocupadas com o "curso ordinário das coisas".

Além do olhar sobre as imagens, a própria experiência de fotografar em campo trouxe marcas à narrativa escrita e também à maneira de se entender como pesquisador. Pela câmera fotográfica, o cotidiano era trazido em seus fragmentos. Era uma outra forma de estar em campo, diferente daquela que buscava as conexões entre os fatos, as causas e os efeitos das coisas. Fotografando, não era possível insistir nas minhas buscas pela linearidade do tempo. José Machado Pais discorre sobre a maneira com que George Simmel, sociólogo do cotidiano, lança seu olhar sobre as coisas cotidianas:

Para Simmel - este pintor do social para quem a sociologia era de resto, uma forma de arte [...] as observações fugazes da realidade constituem a essência de sua sociologia [...]. Neste deslizar do olhar pelo social - nos seus aspectos mais particulares, acidentais e superficiais - o fotografar é um processo de 
capturar o fugaz que o olhar vagabundo do fotógrafo (ou sociólogo) possibilita! (PAIS, 1993, p. 107)

Essa aproximação entre o olhar do pesquisador com o clique instantâneo da câmera fotográfica remete-nos à aceitação de que este nosso olhar é "provisório, interino, experimental", de que "nada nos é dado como produto acabado ou integrado num sistema único e totalitário" e de que, como na fotografia, um foco implica sempre um desfocar. "Não corresponde o ato de mostrar a um processo de centração (atenção) do olhar que implica uma descentralização (desatenção) relativamente ao que circunda o centro da atenção? Não é verdade que o conhecimento arrasta sempre, como a sua sombra, o desconhecido?" (PAIS, 1993, p. 111).

Era preciso aceitar, portanto, que a escola, as situações e os indícios da relação entre professores e monitores ambientais não se entregavam, apenas se insinuavam e tinham de ser imaginados, descobertos, construídos pela pesquisadora. Como na perspectiva sociológica de Simmel, em que "[...] a alma da sociologia da vida quotidiana não está nos fatos mas está no modo como se acerca desses fatos, ditos quotidianos - o modo como os interroga e os revela." (idem, p. 113).

A partir dessas reflexões, paralelas aos registros lineares dos processos da pesquisa, outras foram sendo redigidas com uma escrita que se aproximava ao formato de cenas, instantes permeados por vazios. Esta narrativa fragmentada, metafórica e despreocupada com o compromisso de dar respostas era a tentativa de mostrar os fios soltos e os nós do avesso descontínuo das situações vivenciadas. $\mathrm{E}$ assim, exercitava o desafio de contar tendo o não visto como sombra, o talvez por detrás das afirmações e análises.

A decisão pela linguagem narrativa durante a pesquisa pareceu sempre inevitável.

El tiempo de nuestras vidas es, entonces, tiempo narrado; es el tiempo articulado en una historia; es la historia de nosotros mismos tal como somos capaces de imaginarla, de interpretarla, de contarla y contar(nos)la. Más o menos nítida, más o menos delirante, más o menos fragmentada. Y és así, 
como narración, que cada punto del camino contieno todo el camino [...] Y es en tanto que narrador, el caminante se contiene a sí mismo en toda la extensión de caminar su camino.” (LARROSA, 1996, p. 498).

Ao mesmo tempo em que o ato de narrar as experiências traz à tona identidades, vivenciado como experiência, também as criam e recriam tornando-se, assim, um "mecanismo fundamental de comprensión de sí mismo" (LARROSA, 2000, p. 40). Uma compreensão entendida não como descoberta de uma essência única, mas como abertura de espaços às múltiplas possibilidades de ser. Talvez, na ciência devamos buscar também uma identidade narrativa, uma linguagem em movimento que não se estabelece em um lugar, "encontrando sempre o gosto ácido do devir, da metamorfose" (Idem, p. 111).

\section{Processo Temporal, Lembranças e Invenção}

o registro do trabalho seria esse tipo: armazenar o caso, guardar na caixinha da memória, ou sei lá onde, para depois passar a própria experiência...

Como dito no início deste texto, o trabalho "Entre as Asas da Serra" tem como intenção produzir uma escrita sobre o trabalho de "resgate histórico-cultural" desenvolvido no bairro da Serra, em Iporanga (SP), pela pesquisadora e duas professoras do local. Um local que tem passado por inúmeras mudanças, principalmente relacionadas à implantação do Parque Estadual Turístico do Alto Ribeira (PETAR), com a conseqüente impossibilidade de os moradores locais continuarem suas atividades de extração de recursos naturais da floresta e de agricultura e a chegada da "alternativa" do turismo para a geração de renda e emprego locais.

Mudanças que, para Pedro Silveira (2001), trouxeram diversas modificações nas relações sociais, como as relações de parentesco, de trabalho, religiosas e políticas: "As novas relações de trabalho criadas pela vinda de turistas, ou seja, resultantes da hegemonia das relações de 
trabalho capitalistas, formataram, por um lado, novas relações entre os moradores e, por outro, novas relações entre os moradores e pessoas vindas "de fora"”.

E é nesse movimento de mudança que cresce a idéia de fazer um "resgate histórico-cultural" do bairro. Há uma busca por valores e hábitos que possam ser situados como característicos do lugar, do bairro. Formas de pensar e agir, conhecimentos existentes, relações entre as pessoas. Além disso, esse é um movimento que traz em si uma busca pela diferenciação com relação ao turismo (o outro, o estranho), numa reação a ele e aceitação dele. Não apenas uma aceitação nem apenas uma reação, mas um movimento que está entre essas duas situações.

Uma busca que passa pela criação de possibilidades de identificação dos sujeitos com seu local, com sua história, um movimento de criação de novos sujeitos para o bairro da Serra. Um movimento que traz desejos de nova vida, opções políticas e sonhos.

$\mathrm{E}$, na intenção de produzir uma escrita sobre o trabalho que trouxesse esse movimento, muitos foram os caminhos possíveis de se percorrer e um deles nos chamou a atenção: as discussões sobre tempo e processo temporal. Passado-presente-futuro nem seria futuro-passadopresente nem presente-passado-futuro ou... Sem procurar "resolver" nenhuma questão, procuramos aqui os traços dessas discussões no caminhar do projeto no bairro da Serra e nas possibilidades que se abrem a partir delas.

Pensando em um processo temporal que vai se constituindo, produzindo/inventando sujeitos que são buscados, resgatados e atualizados nas relações com o turismo e nas tradições do bairro. Uma "idéia de passado passa a ser simultânea com o presente, e ao mesmo tempo [em] que há essa simultaneidade passado/presente, um passado começa a ser imaginado ainda por se fazer em um futuro que ainda está por vir" ou ainda, "um passado que não se constitui depois do presente que ele foi, mas ao mesmo tempo" (DELEUZE apud BADIOU, 1997, p. 77).

Não uma história, mas uma memória. E memória que também vai se constituindo. Uma memória que, quando colocada em movimento, quando lembrada, retomada, torna-se narrativa: "a memória estaria guardada em segredo e só voltaria se fosse narrada no 
presente (outro presente), e isto que reaparecesse, no exato momento em que surgisse, deixaria de ser memória e passaria a ser narrativa" (AMARAL. 2000, p. 31). Narrativa de acontecimentos, fluida e também em movimento. Uma memória nômade que traz as relações e as nãorelações entre esses acontecimentos e narrativas que vão se constituindo em seus caminhos. Também não uma negação da história, mas a possibilidade de colocar outros acontecimentos e narrativas para compô-la e produzir novos espaços e novos sujeitos.

Acontecimentos e espaços que transformam e constituem os sujeitos, inventando-os. Com qualquer itinerário que se tome, pode-se passar por diferentes espaços povoados de acontecimentos que vão modelando os sujeitos. $\mathrm{E}$ os sujeitos mesmos se tornam acontecimentos, devires. "O devir-verdade do sujeito, como devir-sujeito do tempo é o que 'faz passar todo o presente para o esquecimento, mas conserva todo o passado na memória'. E se o esquecimento fecha o caminho para todo retorno aquém do presente, é a memória que a partir de então funda a 'necessidade do recomeço' " (DELEUZE apud BADIOU, 1997, p. 81-2).

Mas construir quais novos espaços e novos sujeitos? Constituição esta que passa pela relação com o outro. Outro que aqui escolhemos ser o turismo e todas as mudanças com ele chegadas. A memória, podemos pensá-la aqui, não como um simples refazer o passado, mas um retorno a ele, um retorno que traz ao presente, já de uma forma diferenciada, determinados pontos e idéias que ajudarão a repensar o presente em que se vive e o futuro que se planeja. " A memória na verdade mostra que o passado falta e abre a possibilidade de repetição, sempre em diferença, no futuro" (AMARAL, 2000, p. 32).

É importante ressaltar esse retorno em diferença ... Uma volta, um retorno, um resgate, em diferença. Não uma repetição simples, uma cópia, mas um movimento de retorno que volta diferenciadamente produtivo, repetidamente criativo. "A exigência de rememoração do passado não implica simplesmente a restauração do passado, mas também uma transformação do presente, tal que, se o passado perdido aí for reencontrado, ele [o presente] não fique o mesmo, mas seja, ele também, retomado e transformado" (GAGNEBIN, 1994, p. 19). 
A idéia de montar uma memória da comunidade pode ser vista como uma forma de compartilhar a memória entre as pessoas, um movimento de procurar o passado para repensar o presente e pensar o futuro, de pensar em ações futuras olhando para aspectos do passado vistos com olhos do presente. Mas, nesse movimento, há uma diversidade de produção de significados para os acontecimentos rememorados, para cada fala registrada. O que, nessa diversidade, é considerado importante de se registrar, de se resgatar?

Podemos estender nosso pensamento com a idéia de tradição, pois, em grande parte das discussões e das falas das pessoas envolvidas neste trabalho, a tradição é colocada, muitas vezes, como a justificativa para o trabalho e para a importância do resgate. Do que se fazia e não se faz mais, do que se perdeu, do que não se quer perder, do que se quer resgatar.

... porque as crianças hoje em dia já não conhecem o que os pais conheciam. Então já não têm tanto para oferecer [aos turistas] se a gente não der essa formação, eles não vão ter o que oferecer. As pessoas vêm e querem saber como que é o caipira mesmo, o que você conhece daquela erva, o que é bom para tal coisa, não é mesmo? Quem não conhece isso está ficando para trás, é só as pessoas mais velhas e isso não está sendo passado. Não tem aquela questão de tradição mais, que tinha antes... (Entrevista com Cecília, realizada em 08 de agosto de 2000).

Homi Bhabha (1998) nos coloca outra questão para pensarmos sobre os fatos e pensamentos que são escolhidos como "tradicionais" ou importantes para serem recordados e revividos:

A enunciação da diferença cultural problematiza a divisão binária de passado e presente, tradição e modernidade, no nível da representação cultural e de sua interpelação legítima. Trata-se do problema de como, ao significar o presente, algo vem a ser repetido, relocado e traduzido em nome da tradição, sob a aparência de um passado que não é necessariamente um signo fiel da memória histórica, mas uma estratégia de representação da autoridade em termos do artifício do arcaico. (p. 64-65). 
Nas escolhas de quem entrevistar, nas perguntas proferidas e nas falas das professoras há a busca por elementos que possam identificar as pessoas da Serra, com as quais elas possam se identificar.

Que é o resgate cultural? Então é: fazermos com que o aluno conheça sua própria identidade, sua própria família, sua própria história. Até ontem a Samantha [coordenadora da escola] pediu essa colaboração para as famílias porque não estava tendo esse entendimento ainda, que há necessidade da família de contar a história, a sua própria história, sua identidade, e a gente está trabalhando nesse sentido, [os alunos] estão trazendo, por exemplo, minha história, quando começou, quem são meus pais, meus avós, quando e como eles se conheceram (Fala da professora Lígia, em reunião de HTPC do primário, abril de 2001).

Identificações e identidades que podemos pensar como construídas nas relações entre diferentes culturas, como diz Bhabha, no diálogo, negociação e articulação das diferenças culturais, podendo, com isso, criar uma nova cultura que busque articular essas diferenças e as relações entre o "velho" e o "novo". Uma nova cultura que traz traços das culturas particulares envolvidas, que nunca serão unificadas, mas sim negociadas, interconectadas, traduzidas. A tradição se coloca nesse processo de tradução não pela persistência, não por estar sempre presente de uma mesma forma, mas por sua capacidade de aparecer como justificativa em certos momentos gerados por demandas. Tradição essa que se constrói, que se inventa e que, então, se pode usar como justificativa.

Buscas por saber o que foi modificado e o que poderia voltar, mas pensando um espaço onde seja possível a identificação pelos novos sujeitos que estão se formando, uma formação que se quer que aconteça na relação com o turismo, mas sem que se percam as características peculiares da comunidade e das pessoas que nela habitam. Uma movimentação que se parece com a da alquimia, proposta por Michel Maffesoli (2001): 
Por estágios sucessivos, os materiais brutos, heterogêneos uns em relação aos outros, entram em composição para levar à pedra filosofal, objeto da busca iniciática, naquilo que tem de unificadora. É assim que o longínquo ressoa no que está próximo. Por pouco que se esteja atento a isso, podemos ouvir nas coisas habituais o eco, mais ou menos ensurdecido, de um valor, de um modo de ser ou pensar vindo de outro lugar. As culturas, em seu momento fundador, souberam, assim, misturar no cadinho de sua tradição as múltiplas contribuições do estrangeiro. (p. 102).

Uma movimentação que vai procurar acontecimentos e sentimentos que retomem e revivam aspectos que possam trazer essas identificações com o bairro, mas em uma relação com o outro. Uma movimentação que traz outro movimento em si, o de enraizamento dinâmico:

Todo mundo é de um lugar, e crê, a partir deste lugar, ter ligações, mas para que esse lugar e essas ligações assumam todo o seu significado, é preciso que sejam, realmente ou fantasiosamente, negados, superados, transgredidos. É uma marca do sentimento trágico da existência: nada se resolve numa superação sintética, tudo é vivido em tensão, na incompletude permanente (idem, p. 79).

Uma dinâmica que pode forjar uma familiaridade com o lugar. "Familiaridade das coisas e das gentes, familiaridade do meio ambiente e das paisagens, dos costumes, das tradições e dos hábitos, tudo isso é permanentemente trabalhado por seu contrário. Aquilo que é estranho" (ibidem, p. 102).

Há a busca, neste trabalho, de uma valorização do local, da diferença, da peculiaridade, a busca pela construção de uma nova cultura local, uma cultura que vai sendo modificada na relação com o turismo, com o PETAR. A construção de uma história, de um lugar que foge das tentativas de fixação e estabilizações. Um lugar que passa de espaço a paisagem, passagem entremeada por significados, valores, histórias e sentimentos possíveis de identificações. Uma paisagem que 
se (des)configura nessa relação com as pessoas que ali moram. Paisagens, lugares, pedaços, espaços que são construídos culturalmente.

Relações e identificações múltiplas que Sílvia Serrão aponta que deveriam ser consideradas mais fortemente na criação e manutenção de áreas de proteção ambiental. Para essa autora, um dos motivos pelos quais existem tantos conflitos em áreas de preservação ambiental é a ausência de possibilidades de construção dessas múltiplas identificações com essas áreas, prevalecendo as impostas pelos discursos políticos e científicos. A Educação Ambiental poderia levar aí a contribuição de fazer aparecer e fortalecer discursos, conhecimentos e identificações de outros grupos sociais, novas formas de se ver, ouvir, pensar, sentir e contar sobre esses espaços..

Como já colocamos anteriormente, as mudanças ocorridas no bairro modificaram não só a relação entre as pessoas, mas delas com a natureza e com o conhecimento considerado importante. Muito do conhecimento que pais e avós detinham não mais faz sentido para os jovens dentro da nova ordem do bairro.

Para Boaventura de Souza Santos (1997), o passado pode, reinventado, possibilitar uma nova forma de se pensar, buscando uma transformação social: “o passado é um relato, e nunca um recurso, uma força capaz de irromper num momento de perigo em socorro dos vencidos (...) articular o passado historicamente não significa reconhecê-lo como verdadeiramente foi, significa apoderarmo-nos de uma memória tal como ela relampeja num momento de perigo" (p. 105). Estamos, aqui, falando de construções, de invenções e de opções políticas. Homi Bhabha nos coloca ainda a questão das possibilidades que se abrem a partir de um revistar o passado, podendo nos trazer um posicionamento de manutenção de posições de dominação alicerçados em uma "história" ou possibilitar as mudanças ditas anteriormente e alavancar resistências. A proposta de se fazer um "resgate históricocultural" passa, portanto, por um processo de criação, de invenção de histórias, de tradições, de sujeitos, de identidades. 


\section{As representações de natureza pelos traços da diferença}

$\mathrm{Na}$ dissertação de Fabiana Carvalho, foi possível ler obras de Monteiro Lobato (em que questões sobre meio ambiente e a educação pela leitura são destacadas) e entendê-las em um contexto do qual participam conceitos, explicações, ordens discursivas, formas normativas ou ordenadoras da natureza que podem ser associadas à Ciência (Biologia). Esses elementos remetem-nos a considerar que eles participam dos processos de significação da obra associados à fábula, imaginação e invenção, contextos da literatura infantil. É possível pensar nesse processo de transformação também no campo da educação ambiental, se considerada como contexto.

Reconhecendo que a Ciência participa dessa produção cultural Literatura - e puxando os fios metodológicos dos Estudos Culturais, os significados têm que ser, dentro da obra, (re)criados na relação com as diferenças, eles não funcionam como decalque, cópia de um campo cultural único ou suposto como original. Nesse processo de significação, produzem-se representações culturais, que também são híbridas, nômades, e geram efeitos na organização da leitura e da escritura da obra.

O texto literário remarca a Biologia/Natureza, que faz parte de uma rede instável de textos. Pensando sobre a contextualidade e considerando que lemos dentro do contexto sem que nada exista fora dele, não há espaço para hierarquias definidas, pois tudo está inscrito na mesma rede em que nós estamos. Assim, ao se aproximar de várias dimensões da Natureza para compor sua obra, Monteiro Lobato fez uso, consumo ou se apropriou desses traços culturais, dando-lhes forma, valor e significância.

Significados em passagens que nos fazem refletir sobre as "produções culturais e sobre o quão elas estão marcadas de interesses políticos, ideológicos, ficção e verdade, a regular e organizar nossas condutas e práticas, participando de estabelecimento de normas, regras e convenções através das quais é ordenada e governada a vida social" (WORTMANN, 2001, p. 158). 
Por outro lado, em algumas situações a Biologia participa, nos interstícios do texto, como aquela que "doma, metrifica, mas que também se expande" (DELEUZE e GUATTARI, 1995) e desarruma as lógicas das histórias e as lógicas de uma ordem social, política e ideológica.

As representações foram consideradas constructos culturais, pois, dada a diversidade dos fenômenos culturais, as relações de saberes e poderes são gestadas tanto no cotidiano social quanto no âmbito específico das comunidades científicas com o intuito de ordenação do mundo a partir de saberes e conhecimentos.

A leitura de Stuart Hall (1997) e sua discussão sobre a centralidade da cultura e seu papel constitutivo na vida social nos traz a explicação de que a cultura está inscrita na linguagem e funciona como forma discursiva. Para ele,

a cultura não é nada mais do que a soma de diferentes sistemas de classificação e diferentes formações discursivas aos quais a língua recorre a fim de dar significação às coisas. O próprio termo discurso refere-se a uma série de afirmações, em qualquer domínio, que fornece uma linguagem para se poder falar sobre um assunto e uma forma de produzir um tipo particular de conhecimento. O termo refere-se tanto à produção de conhecimento através da linguagem e da representação, quanto ao modo como o conhecimento é institucionalizado, modelando práticas sociais e pondo novas práticas em funcionamento. ( p. 29).

Os significados são resultantes de seu caráter discursivo e devem ser compreendidos como práticas culturais. Isso não quer dizer que tudo é cultura e que não há nada fora do discurso, mas que toda prática social, na medida em que seja relevante para o significado ou requeira significado para funcionar, tem uma dimensão cultural (HALL, 1997, p. 32). Ao imaginarmos cultura como parte constitutiva das dimensões política, econômica e social, e essas dimensões como partes constitutivas da cultura, podemos dizer que elas funcionam e se constituem mutuamente em sistemas de representação que são partilháveis e intercambiáveis. 
Um outro ponto que pode clarear nossa visão sobre como se dão os sistemas de representações é compreender que eles constroem os significados e os transmitem, ou seja, eles significam, sem fechar em significações ou respostas únicas. Fortemente influenciada pelas observações de Stuart Hall, Maria Lúcia Wortmann (2001), em artigo que foca a história do termo representação, demarca a construção dos significados partilhados e dos sistemas representacionais, quando expõe que os elementos da linguagem - signos e símbolos - fazem parte de nosso mundo natural e material, exercendo a função de construir e transmitir significados. Eles significam e definem, por exemplo, "o que é normal (ou não) em uma cultura, ou quem pertence a um determinado grupo, ou dele é excluído" (HALL, 1997, p. 157), como também "realizam o intercâmbio de interações sociais das quais participamos (...) dando-lhes valor ou significância" (idem, p. 158), em outras palavras, em momentos de contestação e negociação o significado não permanece intacto pela representação, mas muda e se adapta conforme o contexto, circunstâncias e passagens.

Esses estudos organizados em torno da cultura e de seu papel constitutivo privilegiam não somente os pontos de vista dos recortes ambíguos e provocativos, contornos diversos que possam desconstruir o óbvio, fornecendo às pessoas questões e formas de estranhamento que explicitem os significados partilhados culturalmente. A intenção dessa abordagem investigativa é examinar práticas culturais sempre nas suas imbricações com as relações sociais.

Culturas e práticas sociais agregam idéias, atitudes, linguagens, práticas, significados partilhados que emprestam outros significados às práticas e representações produzidas no ato de nomear a ordem e o lugar das coisas.

Esses aportes são trazidos do campo dos Estudos Culturais. Partindo da diversidade metodológica, os Estudos Culturais caracterizam-se pela pluralidade de análises, tecendo redes dentro das quais se podem traçar múltiplos percursos e extrair conclusões variadas e ramificadas. Assim, as categorias e formas de análise revelam-se no instante em que teoria e prática se entrelaçam, associando às práticas e representações diversos e variados temas de investigação que podem ser 
utilizados para mesclar as categorias como raça / etnia, luta de classes / interesses, gêneros / identidades, produção tecnológica / ciência / ambiente, favorecendo deslocamentos que derrubam a visão de que há um único e verdadeiro parâmetro para referenciar o conhecimento.

Relacionar essa noção de cultura com espaços de diferença traz a intenção - bastante tímida - de caminhar por perspectivas desconstrucionistas de Geoffrey Bennington e Jacques Derrida. Os autores postulam que a diferença só aparece na escrita, "obrigando-a a tomar como referência o seu próprio traço escrito (...) se ela quiser dizer da diferença”" (BENNINGTON; DERRIDA, 1996, p. 58). A diferença só vai se constituir na relação com outras diferenças e antecipando os sentidos sempre em relação ao sentido subseqüente. Para esses autores, a diferença (ou traço) supõe uma remarcação na qual todo significante remete para outros significantes, não se chegando nunca a um significado transcendental, ou seja, nenhum significado remete apenas para si mesmo, ou ainda, "um significado não é mais que um significante posto numa certa posição por outros significantes" (idem, p. 34), que gera não sentidos, mas efeitos.

Nessa conceituação, se nomeia o traço, "pois se todo elemento do sistema só possui identidade em sua diferença com relação aos outros elementos, cada elemento está marcado por todos esses que ele não é: ele traz portanto o traço deles" (ibidem, p. 62). A característica marcante do traço é, portanto, sua alteridade, nomear a inscrição do outro nele mesmo; "todo traço é traço de traço" (ibidem, p. 60), encadeamento que se constitui na relação entre as diferenças.

A literatura de Lobato foi considerada um espaço ativo de criação em que as coisas vão se completando. Discursivamente, quando os significados atravessam os corpos modeláveis de Emília e/ou do Visconde, a Biologia ganha valores diferenciados tanto da instância de produção científica quanto no enredo da obra. Talvez essa diferença consista em retardar, reduzir o ritmo, incidir sobre o tempo e o espaço, fundamentais para a narrativa literária e outras produções artísticas como cinema, fotografia ou a pintura.

A inventividade, entretanto, empresta à Ciência explicações e compreensões de como transformar a natureza, discursos que 
tensionam com o prático, com o mais adequado, com o utilitarismo, mas em outras segmentações e fugas, possibilitando a quebra de uma lógica previsível e permitindo o máximo de reforma híbrida, e nessas ações vemos todas as transformações que vêm de novas e inesperadas combinações de seres vivos, idéias malucas, aparatos mecânicos, o outro continuando a ser o mesmo e a diferença (animal - máquina, animal - coisa, animal - utensílio; personagens antropomórficas: bonecos modeláveis - crianças) e é dessa maneira que a novidade entra no mando: nos diálogos pautados com critério científico discutidos por Emília. Os planejamentos de Emília marcam a passagem do traço "fazer ciência" como modelo para se fugir das mudanças organizadas por certos governos.

As contribuições das três dissertações que foram arrastadas até este texto participam de um processo de desnaturalização de pressupostos no campo da educação ambiental (preliminarmente discutidos em AMORIM, 2001) que, visando a transformação da realidade, fixa-os em pontos que apresentam as ciências como formas de entender o mundo a serem privilegiadas nas práticas educativas. Neste artigo, debruçamo-nos em atitudes desconstrucionistas sobre a concepção de natureza/ambiente, sobre a projeção de um sonho de futuro pela negação/superação do presente e captura/recontextualização de tradições e sobre a produção de uma escrita acadêmica que ao excluir a experiência ganha tonalidades de conhecimento científico.

\section{Referências bibliográficas}

AMARAL Adriana Cörner Lopes. Sobre a memória em Jacques Derrida. In: Glenadel, Paula e Nascimento Evandro (org.). Em torno de Jacques Derrida. Rio de Janeiro: 7 Letras, 2000. 
AMORIM, Antonio Carlos R. Mapeando a Educação Ambiental e a Formação de Professores pelos Esfacelamentos da Modernidade. Revista Educação: Teoria e Prática. Rio Claro, vol. 9, no. 16, jan-jul - 2001 e no. 17, jul-dez - 2001.

BACHELARD, Gaston. O Ar e os Sonhos: ensaio sobre a imaginação do movimento. Tradução de Antonio Pádua Danesi. 2a ed. São Paulo: Martins Fontes, 2001. 275p. (Coleção Tópicos).

BADIOU, Alain. Deleuze, o clamor do ser. Rio de Janeiro: Jorge Zahar ed. 1997.

BENNINGTON, Geoffrey \& DERRIDA, Jacques. Derrida. Rio de Janeiro: Jorge Zahar Ed., 1996.

BHABHA, Homi K. O local da cultura. Belo Horizonte: Ed. UFMG, 1998.

FLÜSSER, Vilém. Filosofia da Caixa Preta: ensaios para uma futura filosofia da fotografia. São Paulo: Hucitec, 1985. 92p.

GAGNEBIN, Jeanne Marie. História e Narração em Walter Benjamin. Campinas, SP: Editora da Unicamp, 1994.

HALL, Stuart. Quem precisa de identidade? In: SILVA, Tomaz T. (Org.) Identidade e Diferença: a perspectiva dos estudos culturais. Petrópolis/RJ, Vozes. 1997. p.103-133

HUTCHEON, Linda. The politics of Postmodernism. London: Routledge, 2002

LARROSA, Jorge. Narrativa, Identidad y Desidentificación. In: LARROSA, Jorge. La Experiencia de la Lectura: estudios sobre literatura y formación. Barcelona: Laertes S.A., 1996. p.461-482.

- Notas sobre a Experiência e o Saber da Experiência Leituras da Secretaria Municipal de Campinas, Campinas, SP, n.04, julho de 2001. s/p.

Os Paradoxos da Autoconsciência: um conto com prólogo, epílogo e moral, segundo alguns fragmentos das Confissões de Rosseau. In: LARROSA, Jorge. 
Pedagogia Profana: danças, piruetas e mascaradas. Tradução de Alfredo Veiga-Neto. $3^{\mathrm{a}}$ ed. Belo Horizonte: Autêntica, 2000. p. 21-43.

MEFFESOLI, Michel. Sobre o Nomadismo -vagabundagens pós-modernas. Rio de Janeiro: Record, 2001.

NASCIMENTO, Evandro. Derrida e a Cultura. in Glenadel, Paula e Nascimento Evandro (org.). Em torno de Jacques Derrida. Rio de Janeiro: 7 Letras, 2000.

PAIS, José Machado. Nas Rotas do Quotidiano. Revista Crítica de Ciências Sociais, n.37, junho de 1993. p.105-114.

SAMAIN, Etienne, A Fotografia Tentacular: subsídios críticos para uma arte de ver e pensar. Campinas, SP, 1993 Multimeios -Instituto de Artes, UNICAMP apud AZZOLINO, Adriana A. PAIS. 'Projeto Resgate': a utilização da fotografia no ensino com pesquisa em Ciências Sociais. Campinas, SP: Faculdade de Educação, Unicamp, 1993. Dissertação de Mestrado em Educação.

SILVEIRA, Pedro Castelo Branco. Povo da Terra, Terra do Parque. Dissertação de Mestrado. Instituto de Filosofia e Ciências Humanas/Unicamp, 2001.

WORTMANN, Maria Lúcia Castagna. O uso do termo representação na Educação em Ciências e nos estudos culturais. In: Pro Posições. Campinas: Faculdade de Educação, vol. 12, nº I (34), março, 2001. pp. 151 - 161. 
